\title{
Phenotypic plasticity of body pigmentation in Drosophila: correlated variations between segments
}

\author{
Patricia Gibert ${ }^{\mathrm{a} *}$, Brigitte Moreteau ${ }^{\mathrm{a}}$, \\ Samuel M. Scheiner ${ }^{b}$, Jean R. David ${ }^{a}$ \\ ${ }^{a}$ Laboratoire populations, génétique et évolution, Centre national \\ de la recherche scientifique, 91198 Gif-sur-Yvette cedex, France \\ b Department of Life Sciences, Arizona State University West, \\ P.O. Box 37100, Phoenix AZ 85069, USA
}

(Received 8 September 1997 ; accepted 22 January 1998)

\begin{abstract}
Phenotypic plasticity of body pigmentation (the last three abdominal segments and the mesothorax) was investigated as a function of growth temperature in Drosophila melanogaster and Drosophila simulans. Two populations of each species were analysed, from two French localities with different climatic conditions. For each population, ten isofemale lines were reared at temperatures ranging from 14 to $31^{\circ} \mathrm{C}$. Two methods were used and compared to estimate genetic correlations $\left(r_{\mathrm{g}}\right)$ between segments, a simple method using directly the family mean values $\left(r_{\mathrm{m}}\right)$ and a theoretically better method correcting variances and covariances for family size $\left(r_{\mathrm{c}}\right)$. Both methods produced very similar data but the first one $\left(r_{\mathrm{m}}\right)$ was preferred because it allowed an estimate of $r_{\mathrm{g}}$ in all cases. Genetic and phenotypic correlations decreased regularly with distance between body segments, revealing an antero-posterior gradient: the extension of dark pigmentation is determined by increasingly different genetic systems in more distant segments. Genetic correlations were substantially larger than phenotypic correlations, in opposition to Cheverud's conjecture, although the two sets of values were highly correlated. (C) Inra/Elsevier, Paris

D. melanogaster / D. simulans / genetic correlation / Cheverud's conjecture / isofemale lines
\end{abstract}

Résumé - Plasticité phénotypique de la pigmentation corporelle chez Drosophila : variations corrélées entre segments. La plasticité phénotypique de la pigmentation corporelle (trois derniers segments abdominaux et mésothorax) a été étudiée en fonction de la température chez Drosophila melanogaster et Drosophila simulans. Pour chaque espèce, deux populations ont été analysées, provenant de deux localités françaises ayant

\footnotetext{
* Correspondence and reprints

E-mail: gibert@pge.cnrs-gif.fr
} 
des conditions climatiques différentes. Pour chaque population, dix lignées isofemelles ont été élevées à des températures comprises entre 14 et $31^{\circ} \mathrm{C}$. Deux méthodes ont été utilisées et comparées pour estimer les corrélations génétiques $\left(r_{\mathrm{g}}\right)$ entre segments, une méthode simple utilisant directement les valeurs moyennes des familles $\left(r_{\mathrm{m}}\right)$ et une méthode théoriquement meilleure, corrigeant les variances et les covariances par la taille de la famille $\left(r_{\mathrm{c}}\right)$. Les deux méthodes ont produit des données similaires mais la première $\left(r_{\mathrm{m}}\right)$ a été préférée, car elle permet une estimation dans tous les cas. Les corrélations génétiques et phénotypiques diminuent quand on compare des segments plus distants, révélant un gradient antéro-postérieur. L'extension de la pigmentation noire est déterminée par des systèmes génétiques de plus en plus différents dans des segments plus éloignés. Les corrélations génétiques sont significativement supérieures aux corrélations phénotypiques, ce qui est en opposition avec la conjecture de Cheverud, bien que les deux valeurs soient hautement corrélées. (C) Inra/Elsevier, Paris

D. melanogaster / D. simulans / corrélation génétique / conjecture de Cheverud / lignées isofemelles

\section{INTRODUCTION}

Phenotypic plasticity, the capacity of a single genotype to produce different phenotypes in different environments, is a general property of living organisms. In many cases, for example enzymatic adaptation in bacteria or the production of wingless or winged forms in aphids, the adaptive significance of the polymorphism is obvious $[27,32,36,39]$. The interpretation is, however, far more difficult when a continuous environmental gradient results in continuous variation of the phenotype, the response curve being called the norm of reaction. Numerous cases have been investigated in plants and animals, unravelling two major, but unsolved questions. Are there specific genes acting on the shape of the norms, independently of the mean trait value? Is the shape of the norms acted upon by natural selection, thus exhibiting a specific adaptive value?

Body pigmentation in numerous ectotherm species is known to exhibit broad variation, resulting either from genetic polymorphism or phenotypic plasticity. In the latter case, darker individuals are generally observed at low temperatures [1, $8,9,15,16,18,19,22,25,40]$. Increased melanization at lower temperatures is generally thought to be adaptive for thermoregulation: being darker will favor the absorption of light radiation and thus improve metabolic activity at low temperature; the reverse being true at high temperature.

In Drosophila melanogaster and related species, phenotypic plasticity of pigmentation can be quantified on the mesothorax (a dark pattern with a trident shape) $[2,8]$ and on the tergites of female abdomen segments $[9,13]$. The occurrence of latitudinal clines for the thoracic trident is a major argument in favor of the adaptive significance of pigmentation variations $[2,8,24]$. For abdomen pigmentation, it was also shown that the shapes of reaction norms were different in two French localities differing by their climatic conditions [13]. Reactivity to low developmental temperature was stronger in populations living in the place with more marked seasonal variation and colder winters. The fact that similar results were observed in two sibling species (D. melanogaster and $D$. simulans) enhanced the likelihood that this variation in reaction norm shape was adaptive. In these two species, the shapes of reaction norms are also different according to body segment $[9,13]$. This 
suggests an interaction between developmental genes which specify the formation of adult segments and genes which react to temperature and determine the extension of the black pigment.

The procedure of isofemale lines is not the best method for investigating the genetic architecture of quantitative traits. This procedure has proved however to be extremely useful in ecological genetics for the description of quantitative characters of natural populations $[14,23,26]$. Once isofemale lines have been analysed, we need to extract the maximum information from experimental observations. With respect to heritability, the coefficient of intraclass correlation is generally used as an approximation providing an 'isofemale heritability' [3, 17]. Concerning genetic correlation, the situation is more ambiguous. In various papers [17] genetic correlations have been estimated using a software package, but the exact procedure was not described. On the other hand, the problem was clearly analysed by Via [37], but several solutions were considered.

In the present paper, we accept the inconveniences of isofemale lines, adopt a pragmatic approach, and address three main issues. a) What is the best way for estimating genetic correlations from isofemale lines data? b) To what extent are different genes involved in determining the extension of black pigment in different body segments? c) We tested Cheverud's conjecture [5, 20, 29] that phenotypic correlations are similar to genetic correlations. In other words, phenotypic correlations, which are easier to measure, could be convenient predictors of genetic correlations.

\section{MATERIALS AND METHODS}

\subsection{Populations and experimental procedures}

Sympatric French populations of $D$. melanogaster and D. simulans were collected in a city garden in Villeurbanne near Lyon and a vineyard in Grande Ferrade near Bordeaux. Wild living females were isolated in culture vials to establish isofemale lines. After offspring emergence, ten lines of each species and locality were randomly taken, and from each line ten adult pairs were used as parents of the studied flies. This procedure is necessary to obtain a sufficient progeny number [23]. Investigated flies were thus the second laboratory generation. These parental flies were allowed to oviposit for a few hours in successive vials containing a killed yeast medium [6]. Vials with eggs were then transferred at one of six experimental temperatures (14, $17,21,25,28$ and $31^{\circ} \mathrm{C}$ ) chosen to cover almost the full thermal range compatible with sufficient viability [7]. With this procedure, larval density was kept around 150 per vial, and the use of a high nutrient food reduced crowding effects. On emergence, adults were transferred to fresh food and examined a few days later. From each line at each temperature, ten females were randomly taken and measured.

\subsection{Pigmentation scores}

We analysed pigmentation on the mesonotum and on the last three abdominal segments. Thoracic pigmentation (a dark area with a trident shape, designated as trid) can be analysed in males and females [8] while abdomen pigmentation is variable in females only. In the present work, only females were analysed. The 
extension of black pigment on the last three abdominal tergites (segments 5, 6 and 7) was estimated visually; 11 phenotypic classes were used (see David et al. [9] for details), ranging from 0 (completely yellow) to 10 (completely dark). For the thoracic trident, only four phenotypic classes were used, ranging from 0 (no visible trident) to 3 (dark trident) (see David et al. [8] for details). For comparing thorax and abdominal pigmentation, we standardized their possible range of variation. The trident pigmentation score was thus multiplied by 3.33 , so that variability ranged between 0 and 10 .

Pigmentation variation on either thorax or abdomen is continuous and the establishment of phenotypic classes introduces the possibility of some bias according to observer. We have always been careful about this problem, and verified that identical average scores would be obtained either when the same observer is looking twice at the same flies or when two observers compare their data ([8] and unpublished observations). The same conclusion arises from the high genetic repeatability which is found when successive generations of the same isofemale lines are investigated [14].

\subsection{Data analysis}

Analyses were performed with Statistica [33] and $\mathrm{SAS}^{\circledR}$ [31] software.

With available data (four segments) we calculated six possible pairwise correlations among segments. For each pair of characters, each temperature and each segment, we calculated three different correlations: the total, phenotypic correlation $\left(r_{\mathrm{p}} ; 100\right.$ flies); the correlation between family means $\left(r_{\mathrm{m}} ; 10\right.$ families $)$ and the within family correlation $\left(r_{\mathrm{w}} ; 10\right.$ flies per family).

It was suggested [37] that in many cases $r_{\mathrm{m}}$ could be used as an approximation of the genetic correlation $r_{\mathrm{g}}$. By simulation, Roff and Preziosi [30] showed however that equating $r_{\mathrm{m}}$ to $r_{\mathrm{g}}$ would be biased unless family size $n$ would be sufficiently large $(>20)$. Since in our case family size was less $(n=10)$, we calculated a corrected value $\left(r_{\mathrm{c}}\right)$ between family means, for a better estimate of the genetic correlation, according to the expression:

$$
r_{\mathrm{c}}=\frac{\operatorname{cov}_{\mathrm{m}(X Y)}-1 / n \operatorname{cov}_{\mathrm{w}(X Y)}}{\sqrt{\left(\operatorname{var}_{\mathrm{m}(X)}-1 / n \operatorname{var}_{\mathrm{w}(X)}\right)\left(\operatorname{var}_{\mathrm{m}(Y)}-1 / n \operatorname{var}_{\mathrm{w}(Y)}\right)}}
$$

where $X, Y$ designate the covariates (two segments), $\operatorname{cov}_{\mathrm{m}}$ and $\operatorname{cov}_{\mathrm{w}}$ are the covariances between family means and within families, and $\operatorname{var}_{\mathrm{m}}$ and $\operatorname{var}_{\mathrm{w}}$ the corresponding variances of each variable.

In the present work, numerous correlation values were available for example between the ten females of each line grown at each temperature. These values were then submitted to ANOVA, after $z$ transformation. Results helped us to decide how to pool the data for a more synthetic presentation. For example, in absence of a significant temperature effect, we calculated a single value for each isofemale line, as carried out in table III. Values of the ten lines could then be averaged and a standard error provided. Comparisons of distributions were made with a nonparametric Mann-Whitney test. Since the objective of this paper was focused on biological conclusions, detailed statistical comparisons are not presented. 


\section{RESULTS}

\subsection{An antero-posterior gradient}

Darker flies are obtained at lower growth temperatures but the various segments do not react in the same way and exhibit different levels of plasticity. This interaction between temperature and body segments is illustrated figure 1 for the two species. In $D$. simulans, a regular antero-posterior gradient of increasing darkness is observed at low temperatures $\left(14-21^{\circ} \mathrm{C}\right)$. At higher temperatures an irregularity is observed since segment 6 is darker than segment 7 . In $D$. melanogaster, the anteroposterior gradient is not found for two reasons. One is that the thoracic trident is darker than in $D$. simulans. The second is that segment 6 is darker than segment 7 at all temperatures.

Phenotypic correlations between any pair of segments were calculated for each temperature and population (100 flies in each sample, table $I$ ) and submitted to an ANOVA (not shown) after a $z$ transformation. Higher correlations were observed between adjacent segments while lower values were found when more distant body segments are considered $\left(\mathrm{F}_{(5,67)}=66.49, P<0.001\right)$. Average $r_{\mathrm{p}}$ values decrease from about 0.50 when adjacent segments were correlated (5-6 and 6-7) down to a non-significant 0.07 when correlating segment 7 with trident (figure 2). There are higher correlations in D. melanogaster than in its sibling $\left(\mathrm{F}_{(1,67)}=42.24, P<0.001\right)$, higher values in Villeurbanne than in Bordeaux especially in $D$. melanogaster $\left(\mathrm{F}_{(1.67)}=9.96, P<0.01\right)$, and higher correlations at low temperatures $\left(\mathrm{F}_{(5.67)}=5.97, P<0.001\right)$. Two other correlations were calculated and analysed: the within-line correlation $\left(r_{\mathrm{w}}\right)$ (table III) and the correlation between mean values of the isofemale lines $\left(r_{\mathrm{m}}\right)$ (table $\left.I I\right)$. All values are significantly superior to zero with the exception of thorax-segment 7 (interval 6 , all correlations), and the thorax-segment 6 (interval 5) for the within-line correlations. In each case significant variations were also observed ( figure 2) corresponding to decreasing correlations with increasing segmental distance, thus confirming the antero-posterior gradient.

\subsection{Genetic correlations}

As stated in the method section, the correlation between family means $\left(r_{\mathrm{m}}\right)$ should be corrected when the family size is less than 20 . We calculated these corrected values $r_{\mathrm{c}}$, and compared them to $r_{\mathrm{m}}$. Average values were found to be very similar and not statistically different $\left(D\right.$. melanogaster: $r_{\mathrm{c}}=0.547 \pm 0.0383$, $r_{\mathrm{m}}=0.539 \pm 0.0396, n=64 ; D$. simulans: $r_{\mathrm{c}}=0.441 \pm 0.071, r_{\mathrm{m}}=0.408 \pm 0.0634$, $n=40$ ). Moreover, variations of $r_{\mathrm{c}}$ and $r_{\mathrm{m}}$ were themselves highly correlated (figure 3). Finally, numerous $r_{\mathrm{c}}$ could not be estimated because of either null or negative variances, or of values greater than 1 . Over the whole data set $126 r_{\mathrm{m}}$ were available but only $104 r_{\mathrm{c}}$. We thus decided to use $r_{\mathrm{m}}$ as a better general estimate of $r_{\mathrm{g}}$ (table II) and submitted them to an ANOVA (not shown) after a $z$ transformation.

These values decreased along the antero-posterior gradient (figure 2) $\left(\mathrm{F}_{(5,67)}=\right.$ 55.82, $P<0.001)$. Genetic correlations were on average higher in $D$. melanogaster 


\section{D simulans}

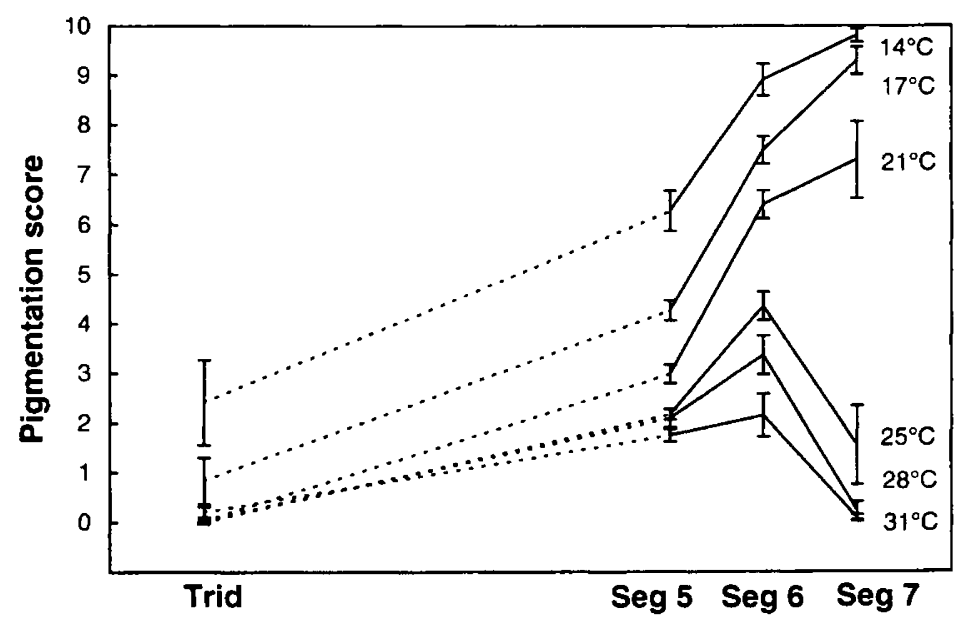

D melanogaster

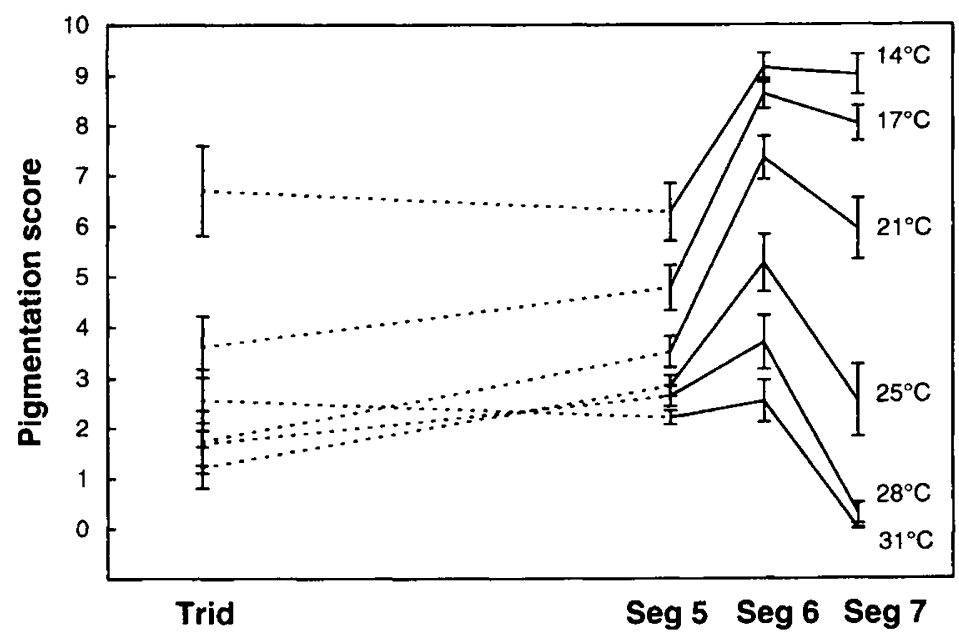

Figure 1. Variation of pigmentation score in different body segments (head is on the left) according to temperature in each species. Original values of trident pigmentation were multiplied by 3.33 in order to have the same variation range as for abdominal segments. 
Table I. Coefficients of phenotypic correlation calculated at each temperature $(n=100)$. Threshold values: 0.20 for $P=0.05,0.26$ for $P=0.01$ and 0.32 for $P=0.001$.

\begin{tabular}{|c|c|c|c|c|c|c|}
\hline & $5-6$ & $5-7$ & $6-7$ & 5-trid & 6-trid & 7-trid \\
\hline \multicolumn{7}{|c|}{ D. melanogaster Bordeaux } \\
\hline $14^{\circ} \mathrm{C}$ & 0.59 & 0.40 & 0.71 & 0.22 & 0.09 & -0.11 \\
\hline $17^{\circ} \mathrm{C}$ & 0.65 & 0.54 & 0.84 & 0.16 & 0.02 & 0.07 \\
\hline $21^{\circ} \mathrm{C}$ & 0.64 & 0.43 & 0.70 & 0.05 & -0.08 & 0.003 \\
\hline $25^{\circ} \mathrm{C}$ & 0.57 & 0.38 & 0.59 & 0.14 & 0.09 & 0.03 \\
\hline $28^{\circ} \mathrm{C}$ & 0.55 & 0.23 & 0.45 & 0.08 & 0.04 & -0.03 \\
\hline $31^{\circ} \mathrm{C}$ & 0.46 & -0.02 & 0.21 & 0.10 & 0.01 & 0.02 \\
\hline Mean \pm s.e. & $0.58 \pm 0.03$ & $0.33 \pm 0.08$ & $0.58 \pm 0.09$ & $0.13 \pm 0.03$ & $0.03 \pm 0.03$ & $-0.003 \pm 0.03$ \\
\hline \multicolumn{7}{|c|}{ D. melanogaster Villeurbanne } \\
\hline $14^{\circ} \mathrm{C}$ & 0.67 & 0.55 & 0.77 & 0.59 & 0.59 & 0.51 \\
\hline $17^{\circ} \mathrm{C}$ & 0.59 & 0.54 & 0.70 & 0.42 & 0.36 & 0.23 \\
\hline $21^{\circ} \mathrm{C}$ & 0.68 & 0.55 & 0.74 & 0.31 & 0.27 & 0.17 \\
\hline $25^{\circ} \mathrm{C}$ & 0.66 & 0.36 & 0.67 & 0.25 & 0.10 & 0.08 \\
\hline $28^{\circ} \mathrm{C}$ & 0.60 & 0.19 & 0.30 & 0.32 & 0.17 & 0.16 \\
\hline $31^{\circ} \mathrm{C}$ & 0.51 & n.c. & n.c. & 0.43 & 0.30 & n.c. \\
\hline Mean \pm s.e. & $0.62 \pm 0.03$ & $0.44 \pm 0.07$ & $0.64 \pm 0.09$ & $0.39 \pm 0.05$ & $0.30 \pm 0.07$ & $0.23 \pm 0.07$ \\
\hline \multicolumn{7}{|c|}{ D. simulans Bordeaux } \\
\hline $14^{\circ} \mathrm{C}$ & 0.57 & 0.35 & 0.63 & 0.21 & -0.09 & -0.14 \\
\hline $17^{\circ} \mathrm{C}$ & 0.45 & 0.41 & 0.56 & 0.04 & 0.002 & -0.25 \\
\hline $21^{\circ} \mathrm{C}$ & 0.47 & 0.23 & 0.59 & 0.03 & 0.01 & -0.01 \\
\hline $25^{\circ} \mathrm{C}$ & 0.25 & 0.17 & 0.53 & n.c. & n.c. & n.c. \\
\hline $28^{\circ} \mathrm{C}$ & 0.65 & 0.24 & 0.31 & 0.15 & 0.20 & 0.77 \\
\hline $31^{\circ} \mathrm{C}$ & 0.65 & 0.16 & 0.13 & 0.06 & 0.09 & -0.05 \\
\hline Mean \pm s.e. & $0.51 \pm 0.06$ & $0.26 \pm 0.04$ & $0.46 \pm 0.08$ & $0.10 \pm 0.04$ & $0.04 \pm 0.05$ & $0.06 \pm 0.18$ \\
\hline \multicolumn{7}{|c|}{ D. simulans Villeurbanne } \\
\hline $14^{\circ} \mathrm{C}$ & 0.50 & n.c. & n.c. & 0.23 & 0.10 & n.c. \\
\hline $17^{\circ} \mathrm{C}$ & 0.52 & 0.33 & 0.51 & -0.06 & -0.06 & -0.06 \\
\hline $21^{\circ} \mathrm{C}$ & 0.39 & 0.22 & 0.53 & n.c. & n.c. & n.c. \\
\hline $25^{\circ} \mathrm{C}$ & 0.39 & 0.21 & 0.63 & n.c. & n.c. & n.c. \\
\hline $28^{\circ} \mathrm{C}$ & 0.58 & 0.12 & 0.27 & n.c. & n.c. & n.c. \\
\hline $31^{\circ} \mathrm{C}$ & 0.34 & 0.03 & 0.30 & 0.10 & 0.15 & 0.04 \\
\hline Mean \pm s.e. & $0.45 \pm 0.04$ & $0.18 \pm 0.05$ & $0.45 \pm 0.07$ & $0.09 \pm 0.08$ & $0.06 \pm 0.06$ & $-0.01 \pm 0.05$ \\
\hline
\end{tabular}

n.c.: not calculated because of a null variance in one trait. The six possible pairwise correlations between segments are indicated as follow: 5,6 and 7: abdomen segments 5, 6 and 7 ; trid: thoracic trident (mesonotum).

than in D. simulans $(0.54$ versus 0.33$)\left(\mathrm{F}_{(1,67)}=37.35, P<0.001\right)$ and higher in Villeurbanne than in Bordeaux in D. melanogaster (0.65 versus 0.44$)\left(\mathrm{F}_{(1,67)}=8.18\right.$, $P<0.001)$.

\subsection{Phenotypic correlations and Cheverud's conjecture}

The phenotypic correlation integrates a genetic and an environmental component of covariation. Environmental components were estimated as the within-line 


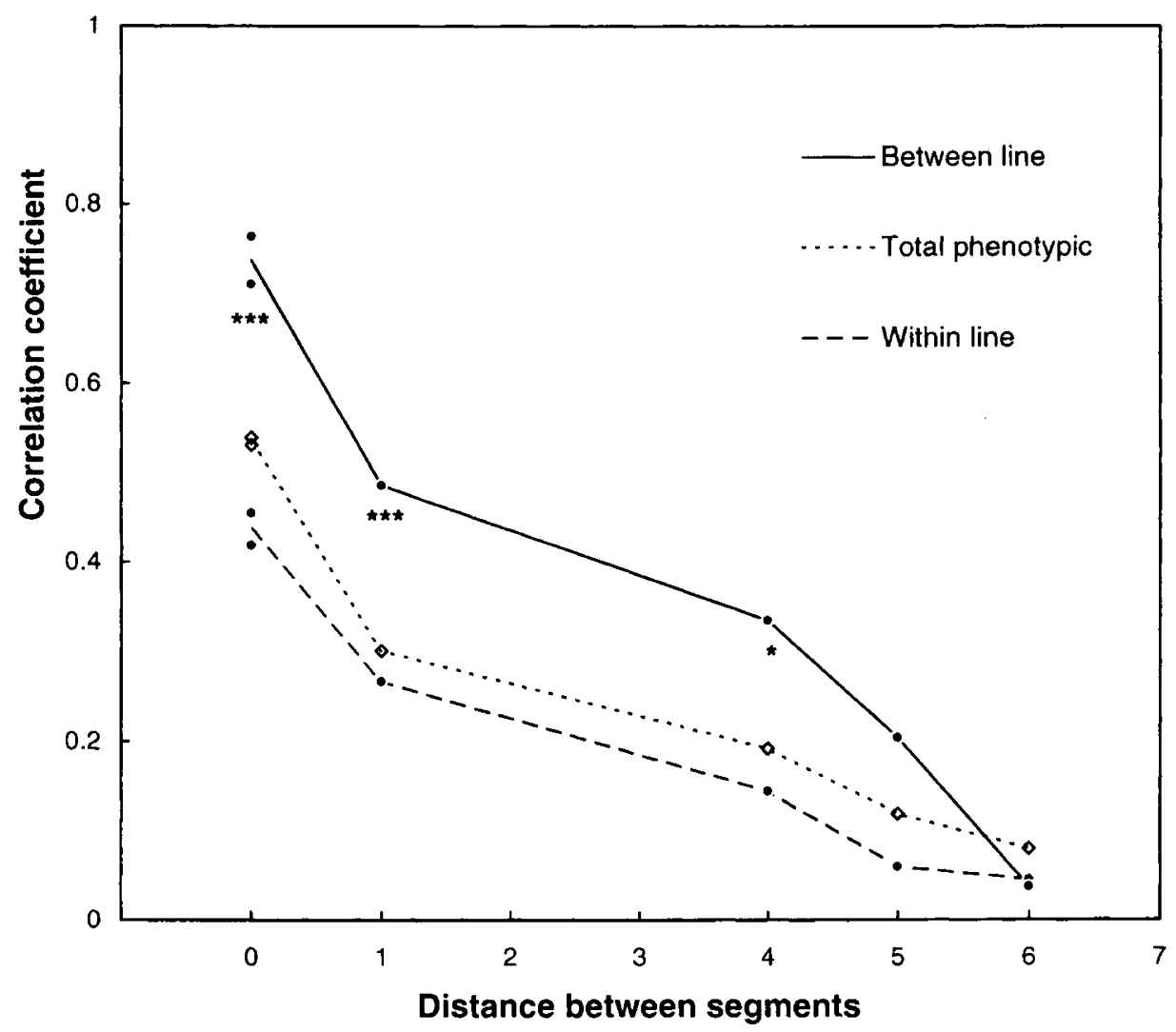

Figure 2. Relationship between average correlation and the distance between correlated segments. Adjacent segments (5-6 or 6-7) were given a distance of zero. Three different correlations were calculated: total phenotypic, within-lines and between-lines which estimates the genetic correlation (see text for details). The within- and between-lines values were compared with a non-parametric Mann-Whitney test: significant differences are indicated on the graph: ${ }^{* * *}: P<0.001,{ }^{* *}: P<0.01$.

correlation. The correlations between segments for the ten females reared in the same vial were calculated for each population, line and temperature. In many cases these correlations could not be calculated because either one average value (mainly the trident of $D$. simulans) or a variance (at extreme temperatures) was null. For each line, correlations were averaged over temperatures, and mean values are given in table III. Average within-line correlations were highly variable between segments, illustrating again the antero-posterior gradient (table III, figure 2).

Cheverud's conjecture [5] states that phenotypic correlations might be convenient approximations of genetic correlations. This requires 1) that the two sets of correlations be highly correlated and 2) that the difference between them be small. Our data clearly show that the two types of correlations were highly correlated 


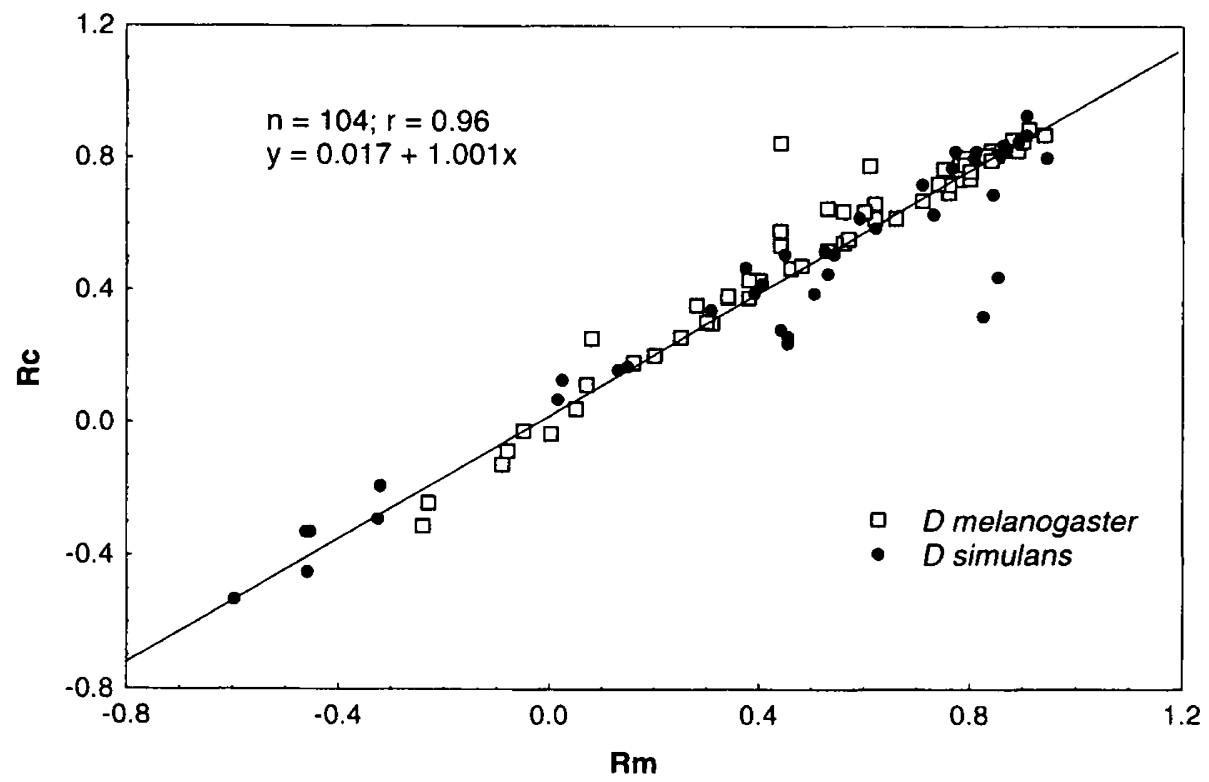

Figure 3. Comparison of the two estimates of the genetic correlation. $r_{\mathrm{m}}$ : correlation calculated directly from family means; $r_{\mathrm{c}}$ : correlation corrected for family size (see text for details).

across species, populations and temperatures (Spearman rank correlation $r_{\mathrm{S}}=0.87$, $n=126, P<0.0001)$. Phenotypic correlations were biased downwards, however. The average difference between the two correlations was 0.14 (s.e. 0.02). In general, genetic correlations were greater than phenotypic correlations, except when all correlations tend to zero.

\section{DISCUSSION AND CONCLUSIONS}

\subsection{An antero-posterior gradient}

There was a progressive decrease of all correlations (phenotypic, genetic and environmental) as body segments became more distant (figure 2). For example, the pigmentation of the mesothorax was positively correlated with that of abdominal segment 5 in more cases than with that of abdominal segment 7 . In previous work $[9,13]$ it was argued that different shapes of reaction norms in different segments demonstrated that their genetic bases were not exactly the same. The regular decrease in the genetic correlations with segmental distance is further proof of that conclusion. Investigating correlations between values of the same trait in different environments is central in understanding the genetics of phenotypic plasticity [10, $37,38]$. Falconer [11] proposed that the same trait measured in two environments could be considered as two different traits related by their genetic correlation. 
Table II. Coefficients of correlation calculated among family means, without correction $\left(r_{\mathrm{m}}\right)$ for each temperature. Each value is based on ten observations. Threshold values: 0.63 for $P=0.05,0.76$ for $P=0.01$ and 0.87 for $P=0.001$.

\begin{tabular}{|c|c|c|c|c|c|c|}
\hline & $5-6$ & $5-7$ & $6-7$ & 5 -trid & 6 -trid & 7-trid \\
\hline \multicolumn{7}{|c|}{ D. melanogaster Bordeaux } \\
\hline $14^{\circ} \mathrm{C}$ & 0.91 & 0.56 & 0.76 & 0.38 & 0.40 & -0.05 \\
\hline $17^{\circ} \mathrm{C}$ & 0.85 & 0.71 & 0.94 & 0.30 & 0.16 & 0.34 \\
\hline $21^{\circ} \mathrm{C}$ & 0.84 & 0.78 & 0.85 & 0.05 & -0.23 & -0.08 \\
\hline $25^{\circ} \mathrm{C}$ & 0.84 & 0.62 & 0.79 & 0.44 & 0.002 & -0.09 \\
\hline $28^{\circ} \mathrm{C}$ & 0.66 & 0.31 & 0.79 & 0.61 & 0.28 & 0.07 \\
\hline $31^{\circ} \mathrm{C}$ & 0.62 & 0.55 & 0.71 & 0.44 & -0.24 & 0.02 \\
\hline Mean \pm s.e. & $0.79 \pm 0.04$ & $0.59 \pm 0.06$ & $0.81 \pm 0.03$ & $0.37 \pm 0.07$ & $0.06 \pm 0.10$ & $0.03 \pm 0.06$ \\
\hline \multicolumn{7}{|c|}{ D. melanogaster Villeurbanne } \\
\hline $14^{\circ} \mathrm{C}$ & 0.89 & 0.76 & 0.89 & 0.80 & 0.86 & 0.74 \\
\hline $17^{\circ} \mathrm{C}$ & 0.83 & 0.78 & 0.88 & 0.53 & 0.62 & 0.25 \\
\hline $21^{\circ} \mathrm{C}$ & 0.84 & 0.79 & 0.90 & 0.46 & 0.60 & 0.38 \\
\hline $25^{\circ} \mathrm{C}$ & 0.78 & 0.57 & 0.80 & 0.83 & 0.53 & 0.34 \\
\hline $28^{\circ} \mathrm{C}$ & 0.80 & 0.44 & 0.68 & 0.56 & 0.20 & 0.08 \\
\hline $31^{\circ} \mathrm{C}$ & 0.78 & n.c. & n.c. & 0.75 & 0.48 & n.c. \\
\hline Mean \pm s.e. & $0.82 \pm 0.02$ & $0.67 \pm 0.06$ & $0.83 \pm 0.04$ & $0.65 \pm 0.06$ & $0.55 \pm 0.08$ & $0.36 \pm 0.10$ \\
\hline
\end{tabular}

D. simulans Bordeaux

$\begin{array}{llllrrr}14^{\circ} \mathrm{C} & 0.47 & 0.34 & 0.82 & 0.16 & -0.29 & -0.53 \\ 17^{\circ} \mathrm{C} & 0.80 & 0.59 & 0.81 & -0.33 & -0.33 & -0.45 \\ 21^{\circ} \mathrm{C} & 0.83 & 0.63 & 0.80 & -0.09 & 0.04 & -0.05 \\ 25^{\circ} \mathrm{C} & 0.50 & 0.25 & 0.72 & \text { n.c. } & \text { n.c. } & \text { n.c. } \\ 28^{\circ} \mathrm{C} & 0.93 & 0.89 & 0.87 & 0.53 & 0.57 & 0.54 \\ 31^{\circ} \mathrm{C} & 0.84 & 0.26 & 0.24 & -0.09 & 0.10 & -0.59\end{array}$

$\begin{array}{lllllll}\text { Mean } \pm \text { s.e. } & 0.73 \pm 0.07 & 0.49 \pm 0.09 & 0.71 \pm 0.09 & 0.04 \pm 0.13 & 0.02 \pm 0.14 & -0.22 \pm 0.19\end{array}$

\begin{tabular}{lcccccc}
$14^{\circ} \mathrm{C}$ & 0.85 & n.c. & n.c. & 0.45 & 0.39 & n.c. \\
$17^{\circ} \mathrm{C}$ & 0.62 & 0.52 & 0.77 & -0.54 & -0.51 & -0.57 \\
$21^{\circ} \mathrm{C}$ & 0.13 & 0.07 & 0.87 & n.c. & n.c. & n.c. \\
$25^{\circ} \mathrm{C}$ & 0.42 & 0.17 & 0.82 & n.c. & n.c. & n.c. \\
$28^{\circ} \mathrm{C}$ & 0.51 & -0.19 & 0.39 & n.c & n.c. & n.c. \\
$31^{\circ} \mathrm{C}$ & 0.51 & 0.28 & 0.69 & 0.45 & 0.44 & 0.32 \\
Mean \pm s.e. & $0.51 \pm 0.09$ & $0.17 \pm 0.10$ & $0.71 \pm 0.08$ & $0.12 \pm 0.27$ & $0.11 \pm 0.25$ & $-0.12 \pm 0.31$ \\
\hline
\end{tabular}

n.c.: not calculated because of a null variance in one trait. The six possible pairwise correlations between segments are indicated as follow: 5,6 and 7: abdomen segments 5,6 and 7 ; trid: thoracic trident (mesonotum).

David et al. [9] showed that when pigmentation scores of the same lines at different temperatures were compared, the correlation decreased regularly when more distant temperatures were considered. This phenomenon was also observed in the present work (results not shown). Here we demonstrated that this pattern also holds for correlations between different segments, at a given temperature. 
Body pigmentation in Drosophila

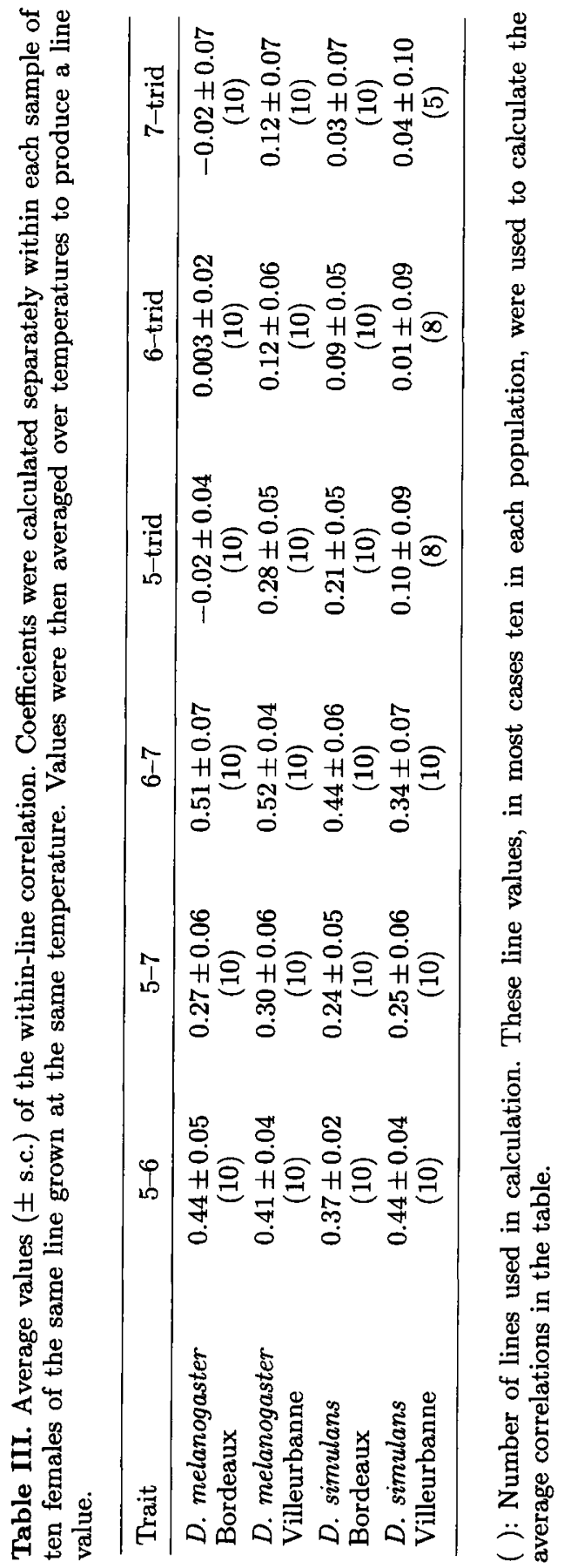


Pigmentation genes are expressed differently across environments and body segments. The fact that pigmentation expression varies according both to body segment and temperature indicates the existence of a complex interaction between internal and external environments. But this interaction has regularities. The embryonic determinism of body segments and the role of homeotic genes are now well known in Drosophila [21]. Our knowledge on the development of the epidermis of adult segments is, however, much less [12] so that any precise hypothesis on the nature of interacting genes seems premature.

\subsection{Phenotypic correlations and Cheverud's conjecture}

For the analysis of natural populations, various fitness-related traits are often measured on different individuals, providing an estimate of phenotypic correlation. Evolutionary theory has emphasised the major significance of trade-offs between characters for explaining the stability of life history strategies [4, 28, 34, 35]. Since evolution is dealing with genetic variations, estimating heritabilities and genetic correlations in natural populations appears as a major issue in evolutionary biology. In various investigations, both phenotypic and genetic correlations have been measured, and in many cases similar values have been observed [5, 29]. This led Cheverud to propose his conjecture according to which phenotypic correlations could be used in many cases as a crude estimate of genetic correlations.

The isofemale line technique provides an estimate of the genetic variability of any trait $[3,17]$. When two traits are measured on the same individual, the between-line covariance also allows an estimate of the genetic correlation. Except when family size is sufficiently large $(n>20)$ the variance and covariance between families should be corrected by the within family terms. In the present work, a total of 144 values of $r_{\mathrm{g}}$ could be calculated, and it was thus possible to test empirically the efficiency of the correction. Quite surprisingly, both methods provided very similar coefficients of correlation. Additionally, in about $17 \%$ of cases, the corrected values could not be calculated. Practically, and at least when family number is quite small, it seems better to estimate the genetic correlation by simply using the family means, as already suggested by Via [37].

We obtained confirmation but also invalidation of Cheverud's [5] conjecture. On the one hand, we found that the two sets of correlations were highly correlated and varied in a parallel way. On the other hand, the genetic correlations were regularly and consistently greater that the phenotypic ones. In our experimental protocol, we kept the environmental variance and covariance (as estimated by the within-line values) as small as possible through the control of the experimental conditions: constant temperature and good larval feeding. This might explain the low value of the within-line correlations. It is, thus, unclear to what extent that Cheverud's conjecture might better apply to natural populations living in a variable environment, or to endothermic species.

\section{ACKNOWLEDGEMENT}

We thank Dr D. Roff for helpful comments and suggestions on this paper. 


\section{REFERENCES}

[1] Capula M., Luiselli L., Reproductive strategies in alpine adders, Vipera berus. The black females bear more often, Acta CEcol. 15 (1994) 207-214.

[2] Capy P., David J.R., Robertson A., Thoracic trident pigmentation in natural populations of Drosophila simulans: a comparison with D. melanogaster, Heredity 61 (1988) 263-268.

[3] Capy P., Pla E., David J.R., Phenotypic and genetic variability of morphometrical traits in natural populations of Drosophila melanogaster and D. simulans. II. Withinpopulation variability, Genet. Sel. Evol. 26 (1994) 15-28.

[4] Charnov E.L., Life History Invariants. Some Explorations of Symmetry in Evolutionary Ecology, Oxford University Press, Oxford, 1993.

[5] Cheverud J.M., A comparison of genetic and phenotypic correlations, Evolution 42 (1988) 958-968.

[6] David J.R., Clavel M.F., Interaction entre le génotype et le milieu d'élevage. Conséquences sur les caractéristiques du développement de la Drosophile, Bull. Biol. Fr. Belg. 99 (1965) 369-378.

[7] David J.R., Allemand R., Van Herrewege J., Cohet Y., Ecophysiology: abiotic factors, in: Ashburner M., Carson H.L., Thompson J.N. (Eds.), The Genetics and Biology of Drosophila, Academic Press, London, 1983, pp. 105-170.

[8] David J.R., Capy P., Payant V., Tsakas S., Thoracic trident pigmentation in Drosophila melanogaster: differentiation of geographical populations, Genet. Sel. Evol. 17 (1985) 211-224.

[9] David J.R., Capy P., Gauthier J.P., Abdominal pigmentation and growth temperatures in Drosophila melanogaster: similarities and differences in the norms of reaction of successive segments, J. Evol. Biol. 3 (1990) 429-445.

[10] De Jong G., Quantitative genetics of reaction norms, J. Evol. Biol. 3 (1990) 447468 .

[11] Falconer D.S., Selection in different environments: effects on environmental sensitivity (reaction norm) and on mean performance, Genet. Res. 56 (1990) 57-70.

[12] Fristrom D., Fristrom J.W., The metamorphic development of the adult epidermis. in: Bate M., Arias A.M. (eds.), The Development of Drosophila melanogaster, Cold Spring Harbor Laboratory Press, USA, 1993, pp. 843-897.

[13] Gibert P., Moreteau B., Moreteau J.C., David J.R., Growth temperature and adult pigmentation in two Drosophila sibling species: an adaptive convergence of reaction norms in sympatric populations? Evolution 50 (1996) 2346-2353.

[14] Gibert P., Moreteau B., Moreteau J.C., David J.R., Genetic variability of quantitative traits in a natural population of Drosophila melanogaster: analysis of wild living flies and of successive laboratory generations, Heredity 80 (1998) 326-335.

[15] Gibson A.R., Falls J.B., Thermal biology of the common gartner snake Thamnopis sirtalis (L). II. The effects of melanism, Ecologia (Berlin) 43 (1979) 99-109.

[16] Goulson D., Determination of larval melanization in the moth, Mamestra brassicae, and the role of melanin in thermoregulation, Heredity 73 (1994) 471-479.

[17] Hoffmann A.A., Parsons P.A., The analysis of quantitative variation in natural populations with isofemale strains, Genet. Sel. Evol. 20 (1988) 87-98.

[18] Kingsolver J.G., Wiernasz D.C., Development, function, and the quantitative genetics of wing melanin pattern in Pieris butterflies, Evolution 45 (1991) 1480-1492.

[19] Kingsolver J.G., Wiernasz D.C., Seasonal polyphenism in wing-melanin pattern and thermoregulatory adaptation in Pieris butterflies, Am. Nat. 137 (1991) 816-830. 
[20] Koots K.R., Gibson J.P., Realized sampling variances of estimates of genetic parameters and the difference between genetic and phenotypic correlations, Genetics 143 (1996) 1409-1416.

[21] Lawrence P.A., The Making of a Fly. The Genetics of Animal Design, Blackwell Scientific Publications, Oxford, 1992.

[22] Monteiro A.F., Brakefield P.M., French V., The evolutionary genetics and developmental basis of wing pattern variation in the butterfly Bicyclus anynana, Evolution 48 (1994) $1147-1157$.

[23] Moreteau B., Capy P., Alonso-Moraga A., Munoz-Serrano A., Stockel J., David J.R., Genetic analysis of quantitative traits in natural populations of Drosophila melanogaster: Isofemale line versus isogroups, Genetica 96 (1995) 207-215.

[24] Munjal A.K., Karan D., Gibert P., Moreteau B., Parkash R., David J.R., Thoracic trident pigmentation in Drosophila melanogaster: latitudinal and altitudinal clines in Indian populations, Genet. Sel. Evol. 29 (1997) 601-610.

[25] Ottenheim M.M., Volmer A.D., Holloway G.J., The genetics of phenotypic plasticity in adult abdominal colour pattern of Eristalis arbustorum (Diptera: Syrphidae), Heredity 77 (1996) 493-499.

[26] Parsons P.A., Isofemale strains and evolutionary strategies in natural populations, Evol. Biol. 13 (1980) 175-217.

[27] Pigliucci M., How organisms respond to environmental changes: from phenotypes to molecules (and vice versa), Trends Ecol. Evol. 11 (1996) 168-173.

[28] Roff D.A., The Evolution of Life Histories. Theory and Analysis, Chapman \& Hall, London, 1992.

[29] Roff D.A., The estimation of genetic correlations from phenotypic correlations: a test of Cheverud's conjecture, Heredity 74 (1995) 481-490.

[30] Roff D.A., Preziosi R., The estimation of the genetic correlation: the use of the jackknife, Heredity 73 (1994) 544-548.

[31] SAS ${ }^{\circledR}$, SAS $^{\circledR}$ user's Guide: statistics, SAS Institute Inc., Cary, NC, 1985.

[32] Schmalhausen I.I., Factors of Evolution: the Theory of Stabilizing Selection, Blakiston, Philadelphia, 1949.

[33] Statistica, Statistica Statsoft Inc., Tulsa, OK, 1995.

[34] Stearns S.C., The Evolution of Life Histories, Oxford University Press, Oxford, 1992.

[35] Stearns S., de Jong G., Newman B., The effects of phenotypic plasticity on genetic correlations, Trends Ecol. Evol. 6 (1991) 122-126.

[36] Travis J., Evaluating the adaptive role of morphological plasticity, in: Wainwright P.C., Reilly S.M. (Eds.), Ecological Morphology, Chicago University Press, Chicago, 1994, pp. 99-122.

[37] Via S., The quantitative genetics of polyphagy in an insect herbivore. II. Genetic correlations in larval performance within and among host plants, Evolution 38 (1984) 896-905.

[38] Via S., Lande R., Genotype-environment interaction and the evolution of phenotypic plasticity, Evolution 39 (1985) 502-522.

[39] Wallace B., Norms of reaction: do they include molecular events, Perspect. Biol. Med. 33 (1990) 323-334.

[40] Watt W.B., Adaptive significance of pigment polymorphisms in Colias butterflies. II. Thermoregulation and photoperiodically controled melanin variation in Colias eurytheme, Proc. Natl. Acad. Sci. USA 63 (1969) 767-774. 